\title{
Laparoscopic Surgery for Colorectal Cancer in Korea: Nationwide Data from 2013 to 2018
}

\section{Sun Jin Park, MD, PhD \\ Kil Yeon Lee, MD, PhD \\ Suk-Hwan Lee, MD, PhD}

Department of Surgery, Kyung Hee University College of Medicine, Seoul, Korea

\begin{abstract}
Purpose
We report nationwide data on the current status of laparoscopic surgery for colorectal cancer (CRC) in Korea.
\end{abstract}

\section{Materials and Methods}

Nationwide data of patients who underwent surgery for CRC from 2013 to 2018 were obtained from the Health Insurance Review \& Assessment Service database. Data and trends of laparoscopy use for colorectal resection over six years were examined.

\section{Results}

In Korea, a total of 117,320 patients underwent surgical resection for CRC from 2013 to 2018. The proportion of laparoscopic resection increased from $64.9 \%$ in 2013 to $78.5 \%$ in 2018. The rate of laparoscopic resection for colon cancer increased from $64.7 \%$ in 2013 to $77.4 \%$ in 2018 . For rectal cancer, the rate of laparoscopic resection increased from $65.4 \%$ to $81.6 \%$. Males accounted for $59.8 \%$ of all patients, but females surpassed males at over 80 years of age. The age of peak incidence was in the 60 s for males and in the $70 \mathrm{~s}$ for females. A steady increase in the number of patients undergoing surgery for CRC was observed over 80 years of age.

\section{Conclusion}

The laparoscopic penetration rate for CRC in Korea continued to increase annually and reached $78.5 \%$ in 2018.
Correspondence: Kil Yeon Lee, MD, PhD

Department of Surgery, Kyung Hee

University Hospital, Kyungheedae-ro 23,

Dongdaemun-gu, Seoul 02447, Korea

Tel: 82-2-958-8241

Fax: 82-2-966-9366

E-mail: kilyeonlee@khu.ac.kr

Received January 15, 2020

Accepted April 4, 2020

Published Online April 6, 2020

\section{Key words}

Colorectal neoplasms, Colorectal surgery, Laparoscopy, Database, Korea

\section{Introduction}

Colorectal cancer (CRC) was the second most common cancer in Korea in 2016 [1], and about 25,000 newly diagnosed cases are anticipated in 2019 [2]. The crude incidence rate of CRC was reported as 55.0 per 100,000 people (65.3 in males, 44.8 in females) in 2016 [1]. The incidence of CRC increased annually from 1999 to 2012 and then began to decline; this phenomenon was observed in other cancers as well
[3]. The survival rate for CRC in Korea has steadily improved with year of diagnosis: the 5-year relative survival rate of $58.0 \%$ in patients diagnosed from 1996 to 2000 increased to 76.3\% in those diagnosed from 2010 to 2014 [3].

We previously reported the first nationwide data on laparoscopic surgery for CRC in Korea, and the laparoscopic resection rate increased from $42.6 \%$ in 2008 to $64.7 \%$ in 2013 [4]. These figures did not include laparoscopic surgery for benign diseases, so the overall laparoscopic surgery rate was expected to be higher for all colorectal diseases. In the early 
period, education and training for laparoscopic surgery was mainly conducted among university hospitals and specialized hospitals. Under the leadership of the academic society, general hospitals are now actively involved in education and dissemination of laparoscopic surgery. Along with increased use of laparoscopic resection in Korea, more efforts are needed to establish structured training programs and improve the quality of CRC treatment [4].

Laparoscopic penetration rate is an important indicator of a nation's healthcare system. There is a lack of literatures regarding comparable nationwide data among countries. We aimed to report the current status of laparoscopic surgery for $\mathrm{CRC}$ in the Republic of Korea.

\section{Materials and Methods}

\section{Data sources}

Nationwide data for patients who underwent surgical resection for CRC from 2013 to 2018 was obtained from the public data service site (http:// www.data.go.kr) provided by the National Information Society Agency (NIA) and from the
Health Insurance Review \& Assessment Service (HIRA). The provided data was anonymized and did not contain personal patient information. The data contained the following information: year of surgical treatment, sex, age group (10-year intervals), main disease code, procedure fee code, number of procedures, and type of surgery (open surgery or laparoscopy).

As previously described [4], data collection criteria were as follows: (1) Data was electronically extracted based on the day of surgical treatment covered by Health Insurance, Medical Aid, or Korean veterans; HIRA completed the review and assessed cost for all individual medical services performed from January 2013 to December 2018. (2) Surgical procedures included all colectomies, colorectal resections, abdominoperineal resections, and total proctocolectomies with or without lymph node dissection. Thus, the procedure fee codes searched for were QA671-673, QA679, QA921-926, QA928, Q0292, Q1261-1262, Q2671-2673, Q2679, and Q29212928 based on the health insurance medical care benefit cost book (2019 Jan. ed., published by the Korean Hospital Association). (3) CRCs were classified according to the Korean Classification of Diseases and Related Health Problems, including colon cancers by location, rectosigmoid junction cancer, and rectal cancer (corresponding disease codes: C18.0-18.9, C19, and C20, respectively).

Table 1. Annual number and percentage of laparoscopic surgeries for colorectal cancer from 2013 to 2018 in Korea

\begin{tabular}{|c|c|c|c|c|}
\hline Year & $\begin{array}{c}\text { Location of } \\
\text { cancer }\end{array}$ & $\begin{array}{c}\text { No. of } \\
\text { surgeries }(\%)\end{array}$ & $\begin{array}{c}\text { No. of } \\
\text { laparoscopies }\end{array}$ & Laparascopy (\%) \\
\hline \multirow[t]{3}{*}{2013} & Rectum & $5,631(28.9)$ & 3,684 & 65.4 \\
\hline & Colon & $13,887(71.1)$ & 8,989 & 64.7 \\
\hline & Total & $19,518(100)$ & 12,673 & 64.9 \\
\hline \multirow[t]{3}{*}{2014} & Rectum & $5,310(27.7)$ & 3,725 & 70.2 \\
\hline & Colon & $13,830(72.3)$ & 9,496 & 68.7 \\
\hline & Total & $19,140(100)$ & 13,221 & 69.1 \\
\hline \multirow[t]{3}{*}{2015} & Rectum & $5,107(27.1)$ & 3,797 & 74.3 \\
\hline & Colon & 13,755 (72.9) & 9,862 & 71.7 \\
\hline & Total & $18,862(100)$ & 13,659 & 72.4 \\
\hline \multirow[t]{3}{*}{2016} & Rectum & $5,171(26.0)$ & 4,003 & 77.4 \\
\hline & Colon & $14,715(74.0)$ & 10,965 & 74.5 \\
\hline & Total & $19,886(100)$ & 14,968 & 75.3 \\
\hline \multirow[t]{3}{*}{2017} & Rectum & $5,267(26.3)$ & 4,181 & 79.4 \\
\hline & Colon & $14,760(73.7)$ & 11,240 & 76.2 \\
\hline & Total & $20,027(100)$ & 15,421 & 77.0 \\
\hline \multirow[t]{3}{*}{2018} & Rectum & $5,233(26.3)$ & 4,269 & 81.6 \\
\hline & Colon & $14,654(73.7)$ & 11,345 & 77.4 \\
\hline & Total & $19,887(100)$ & 15,614 & 78.5 \\
\hline \multirow[t]{3}{*}{ Total } & Rectum & $31,719(27.0)$ & 23,659 & 74.6 \\
\hline & Colon & $85,601(73.0)$ & 61,897 & 72.3 \\
\hline & Total & $117,320(100)$ & 85,556 & 72.9 \\
\hline
\end{tabular}




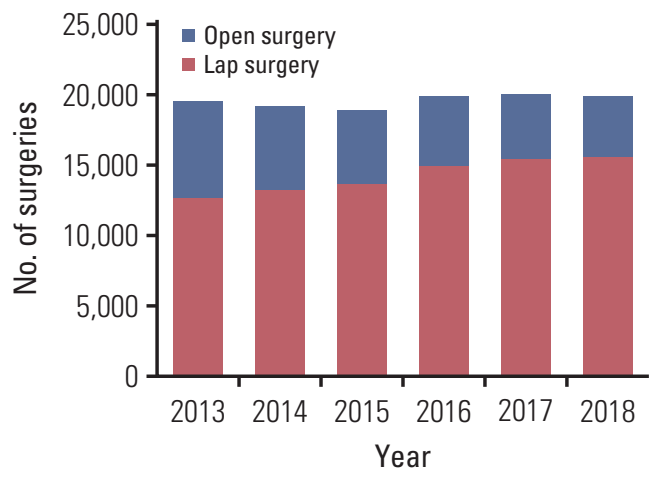

Fig. 1. Current status of laparoscopic surgery for colorectal cancer from 2013 to 2018.

Unlike the previous study [4], this study included Medical Aid recipients, Korean veterans, and patients over 90 years of age, and also included additional codes (newly since July 2017) for patients who underwent ultralow anterior resection (QA928, Q2928) or intersphincteric resection (Q0292), which were previously considered low anterior resection or pullthrough operations. In this study, CRCs were defined within three compartments of the gut: proximal or right colon, distal or left colon, and rectum. The right and left colon are embryologically divided around the proximal two-thirds of the transverse colon, which is the basis for dividing the embryologic midgut and hindgut. However, for convenience and accuracy, the right colon was defined up to the transverse colon (disease code: C180 to C184), and the left colon was defined to include the splenic flexure, descending colon, and sigmoid colon to rectosigmoid junction (disease code: C185 to $\mathrm{C} 187$, and C19) in this study. A retrospective analysis was conducted with the available data. The distributions and changes of age, sex, tumor location, and rate of laparoscopic resection over the six years were evaluated.

\section{Ethical statement}

This study was reviewed by the hospital institutional review board and approved for exemption (IRB number: 2019-09-069).

\section{Results}

From January 2013 to December 2018, a total of 117,320 patients underwent surgery for CRC in Korea; 85,556 (72.9\%) of them underwent laparoscopic surgery (Table 1). The number of surgical cases performed declined by 2015, and then stabilized around 20,000 by 2018 . The laparoscopic surgery rate continued to increase from $64.9 \%$ in 2013 to $78.5 \%$ in 2018 (Fig. 1). For colon cancer, the rate increased from $64.7 \%$ in 2013 to $77.4 \%$ in 2018, and for rectal cancer, this increase was from $65.4 \%$ to $81.6 \%$.

The ratio of rectal cancer to total CRC continued to decline in this study, following the previous study (from $34.8 \%$ in 2008) [4], but has remained at around $26 \%$ since 2016 (Table 1). The most common site of CRC was the rectum, followed by the sigmoid, ascending, and rectosigmoid colon (Fig. 2). The proportion of right colon cancer steadily increased, and that of left colon cancer was relatively stable (Tables 2 and

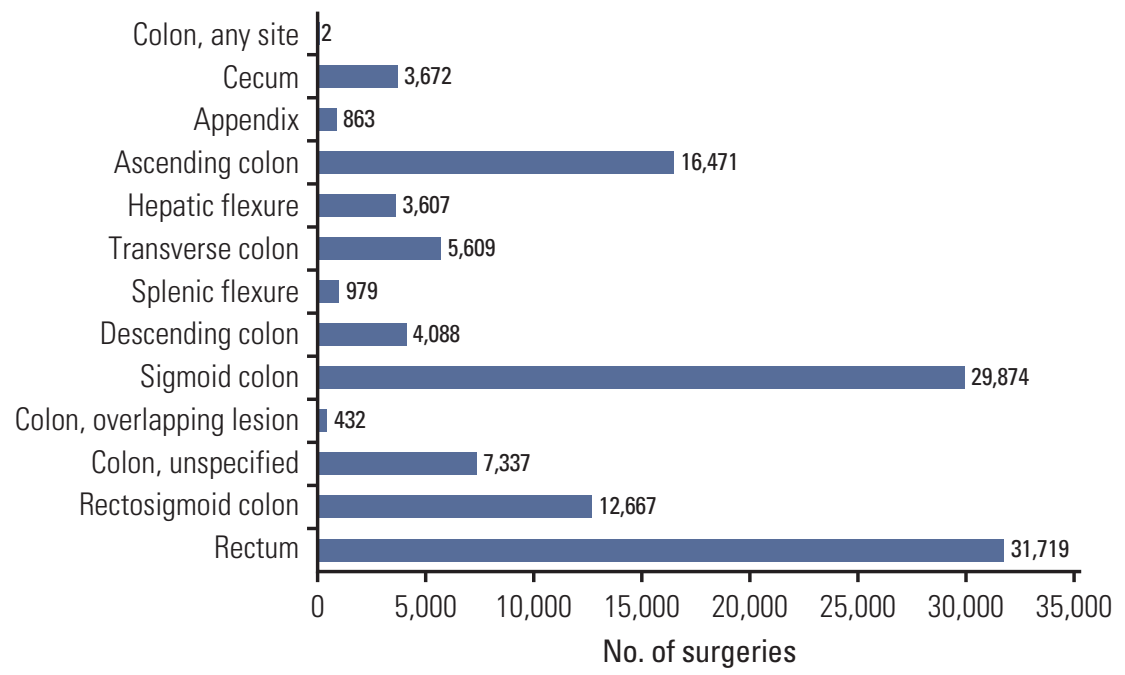

Fig. 2. Tumor locations of surgical patients with colorectal cancer from 2013 to 2018. 
Table 2. Tumor locations of surgical patients with colorectal cancer from 2013 to 2018 in Korea

\begin{tabular}{|c|c|c|c|c|c|c|c|c|}
\hline \multirow{2}{*}{ Location } & \multirow{2}{*}{$\begin{array}{l}\text { Disease } \\
\text { code }\end{array}$} & \multicolumn{6}{|c|}{ Annual number of surgery } & \multirow{2}{*}{ Total } \\
\hline & & 2013 & 2014 & 2015 & 2016 & 2017 & 2018 & \\
\hline Colon, any site & C18 & 1 & 0 & 0 & 1 & 0 & 0 & 2 \\
\hline Cecum & C18.0 & 593 & 571 & 534 & 645 & 633 & 696 & 3,672 \\
\hline Appendix & C18.1 & 111 & 104 & 132 & 139 & 175 & 202 & 863 \\
\hline Ascending colon & C18.2 & 2,566 & 2,610 & 2,650 & 2,805 & 2,875 & 2,965 & 16,471 \\
\hline Hepatic flexure & C18.3 & 583 & 620 & 572 & 609 & 608 & 615 & 3,607 \\
\hline Transverse colon & C18.4 & 928 & 919 & 886 & 929 & 975 & 972 & 5,609 \\
\hline Splenic flexure & C18.5 & 168 & 158 & 141 & 160 & 187 & 165 & 979 \\
\hline Descending colon & C18.6 & 628 & 687 & 664 & 695 & 710 & 704 & 4,088 \\
\hline Sigmoid colon & C18.7 & 4,913 & 4,791 & 4,671 & 5,069 & 5,321 & 5,109 & 29,874 \\
\hline Colon, overlapping lesion & C18.8 & 86 & 48 & 86 & 67 & 73 & 72 & 432 \\
\hline Colon, unspecified & C18.9 & 1,300 & 1,167 & 1,342 & 1,376 & 1,083 & 1,069 & 7,337 \\
\hline Rectosigmoid colon & C19 & 2,010 & 2,155 & 2,077 & 2,220 & 2,120 & 2,085 & 12,667 \\
\hline Rectum & $\mathrm{C} 20$ & 5,631 & 5,310 & 5,107 & 5,171 & 5,267 & 5,233 & 31,719 \\
\hline
\end{tabular}

Table 3. Rate of laparoscopic surgery by colorectal cancer location from 2013 to 2018 (right/ left colon and rectum) in Korea

\begin{tabular}{|c|c|c|c|c|c|c|c|c|}
\hline \multirow{2}{*}{ Location } & \multirow{2}{*}{$\begin{array}{l}\text { Type of } \\
\text { surgery }\end{array}$} & \multicolumn{6}{|c|}{ Annual number of surgery } & \multirow{2}{*}{ Total } \\
\hline & & 2013 & 2014 & 2015 & 2016 & 2017 & 2018 & \\
\hline \multirow[t]{2}{*}{ Right colon ${ }^{\text {a) }}$} & Total & 4,781 & 4,824 & 4,774 & 5,127 & 5,266 & 5,450 & 30,222 \\
\hline & Lap $(\%)$ & $2,944(61.6)$ & $3,217(66.7)$ & $3,350(70.2)$ & $3,790(73.9)$ & $3,914(74.3)$ & $4,128(75.7)$ & $21,343(70.6)$ \\
\hline \multirow[t]{2}{*}{ Left colon ${ }^{\text {b) }}$} & Total & 7,719 & 7,791 & 7,553 & 8,144 & 8,338 & 8,063 & 47,608 \\
\hline & Lap $(\%)$ & $5,338(69.2)$ & $5,591(71.8)$ & $5,661(75.0)$ & $6,205(76.2)$ & $6,514(78.1)$ & $6,391(79.3)$ & $35,700(75.0)$ \\
\hline \multirow[t]{2}{*}{ Rectum } & Total & 5,631 & 5,310 & 5,107 & 5,171 & 5,267 & 5,233 & 31,719 \\
\hline & Lap (\%) & $3,684(65.4)$ & $3,725(70.2)$ & 3,797 (74.3) & $4,003(77.4)$ & $4,181(79.4)$ & $4,269(81.6)$ & $23,659(74.6)$ \\
\hline
\end{tabular}

Values are presented as number $(\%)$. Colons, of any site, overlapping lesions, and unspecified lesions were excluded from

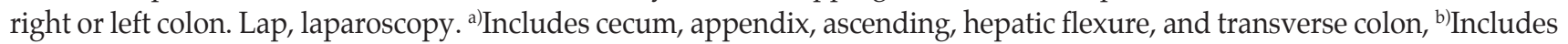
splenic flexure, descending, sigmoid, and rectosigmoid colon.

3). Among right colon cancers, the number of cecum, appendix, and ascending colon cancers steadily increased, while that of hepatic, transverse, and splenic colon cancers was relatively steady for six years. The average rate of laparoscopic surgery in the right colon, left colon, and rectum was $70.6 \%$, $75.0 \%$, and $74.6 \%$, respectively, and continued to increase every year; the average rate of laparoscopic surgery in the right colon increased from $61.6 \%$ to $75.7 \%$, that of the left colon increased from $69.2 \%$ to $79.3 \%$, and that of the rectum increased from $65.4 \%$ to $81.6 \%$ (Table 3). The three major surgical procedures for CRC were low anterior resection, hemicolectomy (right or left), and anterior resection, and the rates of laparoscopic surgery in 2018 were $84.2 \%, 77.4 \%$, and $85.7 \%$, respectively (Table 4).

The number of patients who underwent surgical resection for CRC increased gradually with age, and the peak incidences in males and females were in the 60 s and 70 s, respec- tively. The overall sex ratio was 6 to 4 for males to females, but the ratio was reversed in the age group of 80 or more, in which women were dominant (Fig. 3). The number of patients in their 60s and 70s remained stable, but there were fewer patients in their 40 s and 50 s and steadily more patients in their 80's and 90's over the 6 years (Table 5).

\section{Discussion}

We report nationwide data on surgery for CRC from 2013 to 2018 following the previous study (2008 to 2013). The method used here differed from that of the previous study. First, the previous study included medical insurance data only, while this study included medical insurance, medical 
Table 4. Annual number and rate of laparoscopic surgeries by surgical procedure from 2013 to 2018 in Korea

\begin{tabular}{|c|c|c|c|c|c|c|c|c|}
\hline \multirow{2}{*}{ Procedure } & \multirow{2}{*}{$\begin{array}{l}\text { Type of } \\
\text { surgery }\end{array}$} & \multicolumn{6}{|c|}{ Year } & \multirow{2}{*}{ Total } \\
\hline & & 2013 & 2014 & 2015 & 2016 & 2017 & 2018 & \\
\hline \multirow[t]{2}{*}{ Segmental resection } & Total & 676 & 594 & 577 & 540 & 593 & 603 & 3,583 \\
\hline & Lap (\%) & $268(39.6)$ & $285(48.0)$ & $259(44.9)$ & $255(47.2)$ & 312 (52.6) & $327(54.2)$ & $1,706(47.6)$ \\
\hline \multirow[t]{2}{*}{ Hemicolectomy } & Total & 5,704 & 5,740 & 5,740 & 6,288 & 6,214 & 6,350 & 36,036 \\
\hline & Lap (\%) & $3,503(61.4)$ & $3,834(66.8)$ & $4,049(70.5)$ & $4,654(74.0)$ & $4,672(75.2)$ & $4,916(77.4)$ & $25,628(71.1)$ \\
\hline \multirow[t]{2}{*}{$\mathrm{AR}$} & Total & 4,942 & 4,790 & 4,861 & 5,147 & 5,263 & 5,065 & 30,068 \\
\hline & Lap (\%) & $3,760(76.1)$ & $3,774(78.8)$ & $3,940(81.1)$ & $4,277(83.1)$ & 4,494 (85.4) & $4,342(85.7)$ & $24,587(81.8)$ \\
\hline \multirow[t]{2}{*}{ LAR } & Total & 6,609 & 6,394 & 6,154 & 6,381 & 6,313 & 6,314 & 38,165 \\
\hline & Lap (\%) & $4,630(70.1)$ & $4,742(74.2)$ & $4,802(78.0)$ & $5,157(80.8)$ & $5,231(82.9)$ & $5,318(84.2)$ & $29,880(78.3)$ \\
\hline \multirow[t]{2}{*}{ Subtotal colectomy } & Total & 200 & 209 & 238 & 185 & 227 & 225 & 1,284 \\
\hline & Lap (\%) & $78(39.0)$ & $82(39.2)$ & $103(43.3)$ & $81(43.8)$ & $96(42.3)$ & $105(46.7)$ & $545(42.4)$ \\
\hline \multirow[t]{2}{*}{ Total colectomy } & Total & 178 & 185 & 154 & 140 & 172 & 164 & 993 \\
\hline & Lap (\%) & $41(23.0)$ & $54(29.2)$ & 49 (31.8) & 47 (33.6) & $61(35.5)$ & $59(36.0)$ & 311 (31.3) \\
\hline \multirow[t]{2}{*}{ Hartmann procedure } & Total & 571 & 603 & 599 & 646 & 674 & 677 & 3,770 \\
\hline & Lap (\%) & $103(18.0)$ & $130(21.6)$ & $154(25.7)$ & $163(25.2)$ & $210(31.2)$ & $238(35.2)$ & $998(26.5)$ \\
\hline \multirow[t]{2}{*}{$\mathrm{APR}$} & Total & 562 & 567 & 485 & 501 & 501 & 433 & 3,049 \\
\hline & Lap (\%) & $261(46.4)$ & 294 (51.9) & $274(56.5)$ & 297 (59.3) & $301(60.1)$ & $278(64.2)$ & 1,705 (55.9) \\
\hline \multirow[t]{2}{*}{ TPC with ileostomy } & Total & 33 & 19 & 19 & 24 & 29 & 23 & 147 \\
\hline & Lap $(\%)$ & $10(30.3)$ & $3(15.8)$ & $4(21.1)$ & $14(58.3)$ & $15(51.7)$ & $11(47.8)$ & $57(38.8)$ \\
\hline \multirow[t]{2}{*}{ TPC with IPAA } & Total & 43 & 39 & 35 & 34 & 41 & 33 & 225 \\
\hline & Lap (\%) & $19(44.2)$ & $23(59.0)$ & 25 (71.4) & $23(67.6)$ & $29(70.7)$ & $20(60.6)$ & 139 (61.8) \\
\hline
\end{tabular}

Values are presented as number (\%). Lap, laparoscopy; AR, anterior resection; LAR, low anterior resection; APR, abdominoperineal resection; TPC, total proctocolectomy; IPAA, ileal pouch anal anastomosis.

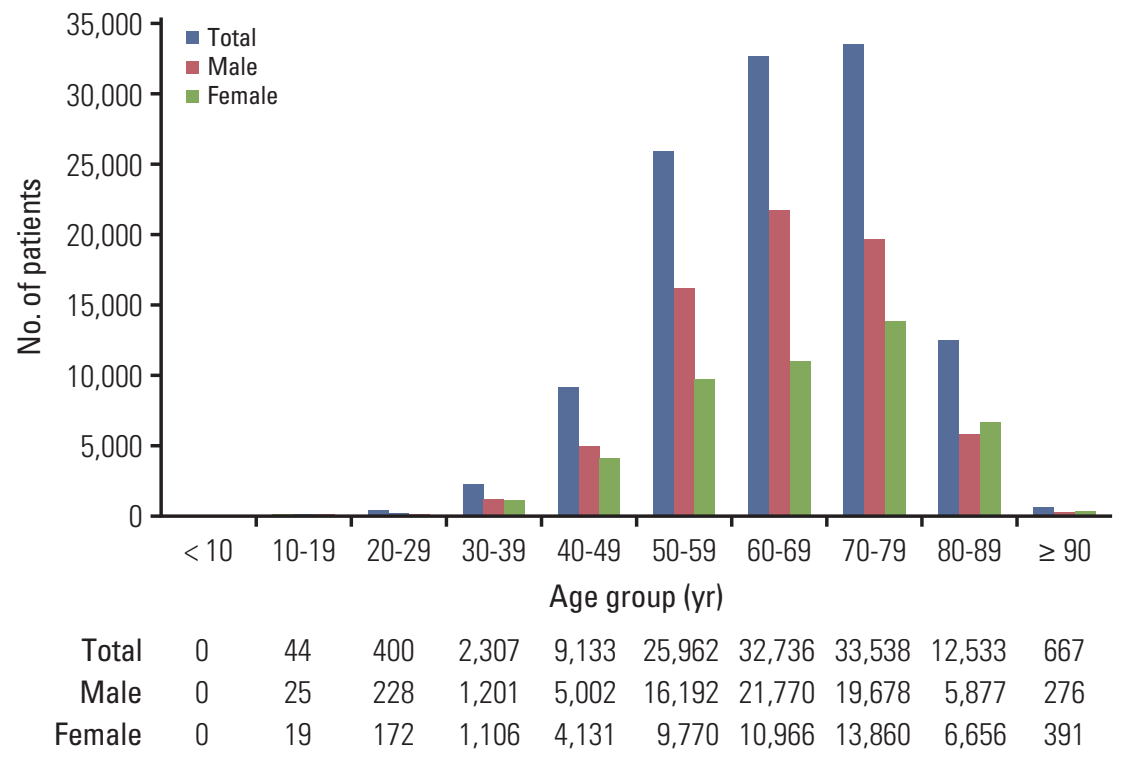

Fig. 3. Distribution of surgical patients with colorectal cancer by age and sex from 2013 to 2018. 


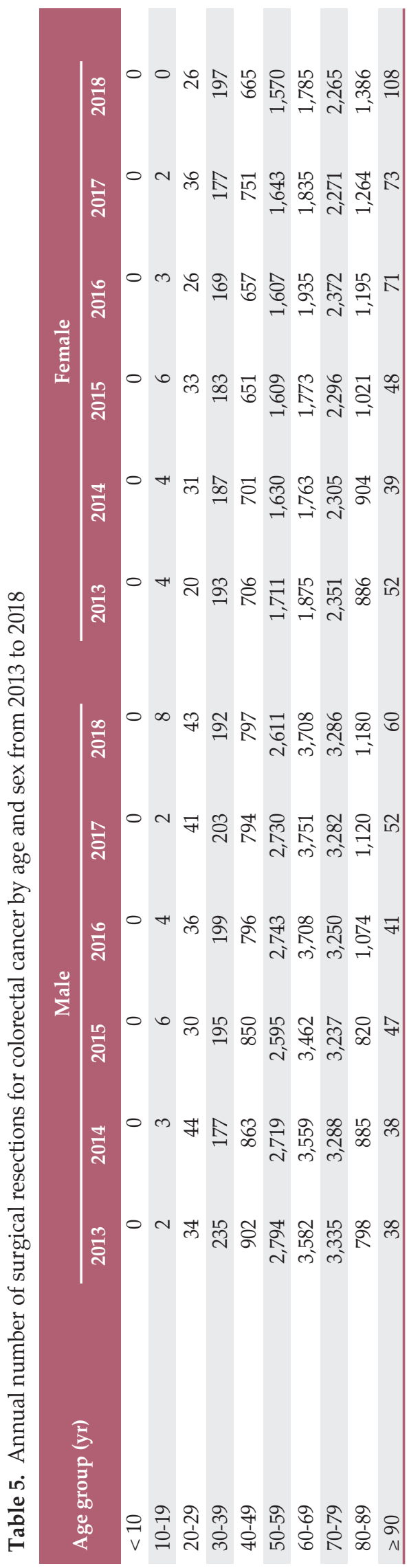

aid, and veteran data. Second, the previous study included only patients up to 89 years of age, while this study also included patients over 90 years old. For comparison, the data for 2013 overlapped with this study, and the number of surgeries in 2013 year increased by about $3.8 \%$ compared to the previous study. Third, this study included new surgical procedure codes that were established since July 2017. These procedures are ultralow anterior resection (QA928, Q2928) and intersphincteric resection (Q0292), which were previously unified as low anterior resection or pull-through operation.

In Korea, the proportion of patients with CRC who underwent laparoscopic surgery has continued to grow. Among patients who underwent surgery for CRC, $64.9 \%$ underwent laparoscopic resection in 2013 and $78.5 \%$ underwent laparoscopic resection in 2018. The proportion of $42.6 \%$ in 2008 continued to increase by more than $35 \%$ in 10 years [4]. The increasing use of laparoscopy in a short time may be because most surgeries for CRC are performed by professional colorectal surgeons in tertiary university hospitals or specialized colorectal hospitals in Korea. However, despite the high rate of laparoscopic surgery in Korea, continuous efforts are needed to improve the quality of surgery. Education and training of resident and fellow should be conducted to nurture competent surgeons in laparoscopy, and quality control programs are needed to reduce the discrepancy in treatment among surgeons and hospitals. There are few literatures on comparable nationwide data between countries. A study based on the 2010-2015 National Cancer Database in the United States reported that $51 \%$ of rectal cancer patients had minimally invasive surgery [5]. Japan Society for Endoscopic Surgery reported that a penetration rate of laparoscopic surgery for CRC was $58 \%$ in 2013 [6]. An Italian study based on a large administrative database reported that the age-adjusted rate of laparoscopy for colon cancer was 36.0\% in 2013 [7]. A population-based study from the Dutch Surgical Colorectal Audit reported that the overall laparoscopic resection rate for CRC was 58\% in 2013 [8].

The annual number of patients who underwent surgery for CRC increased from 15,197 in 2008 to 19,887 in 2018 [4]. However, the demographic distribution of patients undergoing surgery for the latter 6 years was similar to that for the former 6 years. The sex ratio was 6:4 for males to females, with males dominant in the overall population. However, the sex ratio was reversed with female predominance in those 80 years old and above. This phenomenon was related to reports from Cancer Statistics in Korea that CRC was the most common cancer among females aged 65 and over since 2008 [1-3,9]. Peak incidences were in the 60s in men and in the 70s in women. These features were consistently observed compared to the previous study. Annual changes according to age group reflected an aging population. The number of 
surgical patients in the age groups of 80's and 90's or older continued to increase every year.

It was observed that the proportion of rectal cancer in the total CRC continued to decline, which was $34.8 \%$ in 2008 [4], and has remained around $26 \%$ since 2016. A large-scale, retrospective cohort study of a single institution in Korea including 12,631 CRC patients from 1994 to 2013 reported $39 \%$ of rectal cancer [10]. It is uncertain whether this observation was actually associated with the incidence of rectal cancer in Korea, or whether the number of surgical resections has decreased due to increased endoscopic resection. Although increasing rates of laparoscopic surgery are observed annually for all CRCs, a relatively lower rate of laparoscopic surgery, particularly in right colon cancers, was observed again in this study. Further study is needed to address these observations.

There are some limitations in this study. Although this study included almost all patients who have had CRC surgery in Korea, it did not include detailed information on surgical or oncologic results, survival, or outcomes across hospitals. Some of these results are included in another database from the HIRA Benefit Quality Assessment for CRC and have been annually surveyed in Korea. However, this database is not yet open to the public. Even when it is available, corresponding data are not linked between the two databases and survival data are not available for the protection of personal information. We hope to have an integrated database soon.

In conclusion, the laparoscopic penetration rate for CRC in Korea continues to increase each year. The laparoscopic surgery rate of $42.6 \%$ in 2008 steadily increased by more than $35 \%$ over 10 years and reached $78.5 \%$ in 2018. In particular, the rate of laparoscopic surgery for rectal cancer was $81.6 \%$, whereas the rate for right colon cancer was relatively low. As an aging population, there was a steady increase in the number of patients undergoing surgery for CRC over 80 years of age.

\section{Conflicts of Interest}

Conflicts of interest relevant to this article was not reported.

\section{References}

1. Jung KW, Won YJ, Kong HJ, Lee ES. Cancer statistics in Korea: incidence, mortality, survival, and prevalence in 2016. Cancer Res Treat. 2019;51:417-30.

2. Jung KW, Won YJ, Kong HJ, Lee ES. Prediction of cancer incidence and mortality in Korea, 2019. Cancer Res Treat. 2019;51: 431-7.

3. Jung KW, Won YJ, Oh CM, Kong HJ, Lee DH, Lee KH, et al. Cancer statistics in Korea: incidence, mortality, survival, and prevalence in 2014. Cancer Res Treat. 2017;49:292-305.

4. Park SJ, Lee KY, Lee SH. Laparoscopic surgery for colorectal cancer in Korea: nationwide data from 2008 2013. J Minim Invasive Surg. 2015;18:39-43.

5. Gilmore B, Adam MA, Rhodin K, Turner MC, Ezekian B, Mantyh CR, et al. Evolution of minimally invasive surgery for rectal cancer: update from the national cancer database. Surg Endosc. 2020 Feb 28 [Epub]. https:// doi.org/10.1007/ s00464020-07393-y.

6. Inomata M, Akagi T, Nakajima K. Current status of laparo- scopic surgery for colorectal cancer based on the evidence of JCOG0404 trial. Nihon Rinsho. 2016;74:1903-8.

7. Saia M, Buja A, Mantoan D, Agresta F, Baldo V. Colon cancer surgery: a retrospective study based on a large administrative database. Surg Laparosc Endosc Percutan Tech. 2016;26:e12631.

8. Gietelink L, Wouters MW, Bemelman WA, Dekker JW, Tollenaar RA, Tanis PJ, et al. Reduced 30-day mortality after laparoscopic colorectal cancer surgery: a population based study from the Dutch Surgical Colorectal Audit (DSCA). Ann Surg. 2016;264:135-40.

9. Jung KW, Park S, Kong HJ, Won YJ, Lee JY, Park EC, et al. Cancer statistics in Korea: incidence, mortality, survival, and prevalence in 2008. Cancer Res Treat. 2011;43:1-11.

10. Yun SO, Cho YB, Lee WY, Kim HC, Yun SH, Park YA, et al. Clinical significance of signet-ring-cell colorectal cancer as a prognostic factor. Ann Coloproctol. 2017;33:232-8. 